\title{
ESTAFILOCOCCIA POR LESÃO ACNEIFORME COM DESENVOLVIMENTO AGUDO DE PNEUMOPATIA: RELATO DE CASO
}

\author{
Ana Lucia Batista da SILVA ${ }^{*}$, Andrei Vargas Vieira LOPES ${ }^{1}$, Hugo Valinho FRANCISCO² \& Nélio Artiles \\ FREITAS ${ }^{1}$
}

\begin{abstract}
1 Faculdade de Medicina de Campos. Campos dos Goytacazes, Rio de Janeiro, Brasil.
2 Hospital dos Plantadores de Cana - HPC. Campos dos Goytacazes, Rio de Janeiro, Brasil.

Autor para correspondência: ana.batista.15@icloud.com
\end{abstract}

DOI: http://dx.doi.org/10.18571/acbm.192

\section{RESUMO}

Objetivo: Relatar um caso de pneumopatia estafilocócica desencadeada por disseminação hematogênica secundária à infecção de pele. Método: Relato de caso baseado em prontuário de internação hospitalar, dados laboratoriais, exames radiológicos e resposta terapêutica. Relato de caso: Paciente masculino, 15 anos, natural de Rio das Ostras, admitido na enfermaria de Clínica Médica do HPC devido a febre, dispneia progressiva e dor torácica tipo pleurítica, com evolução de piora rápida, sendo em seguida transferido para a UTI. Na avaliação inicial apontou lesão em lábio inferior sugestiva de Herpes simples com evolução de 10 dias e sem melhora com o uso medicação tópica (Aciclovir). Ao exame físico apresentava edema importante em lábio inferior com tecido de granulação e ausculta pulmonar alterada. Foi iniciada terapia empírica com Vancomicina e Piperacilina/Tazobactam. Após 10 dias de internação na UTI, houve melhora considerável do quadro com a terapia instituída. Conclusão: A investigação de infecção estafilocócica deve ser sempre instituída perante a verificação de pneumopatia grave associada à lesão cutânea infecciosa.

Palavras chave: Pneumopatia estafilocócica; Lesão cutânea; Disseminação hematogênica.

\begin{abstract}
Objective: To report a case of staphylococcal pneumopathy triggered by hematogenous dissemination secondary to skin infection. Method: Case report based on hospital records, laboratory data, radiological exams and therapeutic response. Case report: A 15-year-old male patient from Rio das Ostras was admitted to the HPC Medical Clinic ward due to fever, progressive dyspnea and pleuritic chest pain, with a rapid worsening. He was then transferred to the Intensive Care Unit (ICU). In the initial evaluation, he indicated lesion in the lower lip suggestive of Herpes simplex with evolution of 10 days and without improvement with topical medication (Acyclovir). On physical examination, the patient had an important swollen lower lip with granulation tissue and abnormal pulmonary auscultation. Empirical therapy with Vancomycin and Piperacillin/Tazobactam was started. After 10 days of antibiotic therapy in the ICU, there was a considerable improvement in the clinical condicion. Conclusion: There should always be an investigation for staphylococcal infection in the presence of severe pneumopathy associated with infectious cutaneous lesion.
\end{abstract}

Keywords: Staphylococcal pneumopathy; Skin lesion; Hematogenous Dissemination.

\section{Introdução}

Os Estafilococos são classificados como bactérias cocos Gram positivas pertencentes à família Micrococcaceae e se assemelham a cachos de uvas quando corados por Gram. Por fazerem 


\section{Biomedica Brasiliensia}

parte da flora humana normal, não é incomum que indivíduos sadios tenham colonização persistente ou transitória. Podem ser encontrados na parte anterior da narina, pele lesada, vagina, axila e períneo, locais estes que funcionam como reservatório de cepas para futuras infecções. Entretanto a taxa de colonização é maior entre diabéticos em insulinoterapia, soropositivos, pacientes em hemodiálise e indivíduos com alguma lesão de pele.

$\mathrm{O}$ estafilococo, do ponto de vista infeccioso, é considerado uma bactéria oportunista. $\mathrm{Na}$ vigência de uma colonização tecidual ele pode gerar uma infecção localizada que, quando não contida pela barreira imunológica do hospedeiro, dissemina-se. Neste contexto ele pode causar desde uma infecção leve, como uma piodermite, até um acometimento sistêmico com risco de morte, como na Síndrome do Choque Tóxico. (LONG, DAN L. et al 2013 p.1160-1161)

As espécies de maior importância são o Staphylococcus aureus (ou coagulase-positiva) e o Staphylococcus epidermidis (ou coagulase-negativa). A microflora humana normal possui como principal componente o estafilococo coagulase negativa que raramente causa infecção em pessoas sadias. A produção de coagulase é um teste importante na identificação do Staphylococcus aureus, principal responsável por causar infecções agudas nos pacientes (VERONESI R.; FOCACIA R. 2015 p. 1095-1096). Esse trabalho objetiva relatar um caso de pneumopatia estafilocócica desencadeada por disseminação hematogênica secundária à infecção de pele.

\section{Relato de Caso}

Paciente D.R., masculino, 15 anos, natural de Rio das Ostras, é admitido no Serviço de Clínica Médica do Hospital dos Plantadores de Cana referindo que há aproximadamente 10 dias observou lesão em lábio inferior sugestiva de acne, tendo realizado a expressão da mesma. Fez uso de gelo e pasta de dente no local sem melhora. Evoluiu com piora da lesão, associada a sensação de febre (não aferida), dor ventilatório dependente em região subcostal ( $5^{\mathrm{a}}$ a $7^{\mathrm{a}}$ costelas) à esquerda e em coluna torácica. Procurou atendimento em instituição hospitalar de Rio das Ostras onde ficou internado por 5 dias em tratamento com Aciclovir por suspeita de lesão por Herpes simples em lábio inferior, além de antibióticos, os quais não soube informar. Recebeu alta com remissão da dor torácica e melhora parcial da lesão labial. Em casa evoluiu novamente com febre, dor torácica ventilatório dependente e em coluna torácica.

Ao exame físico apresentava edema importante em lábio inferior. FC: 120 bpm, estertores subcreptantes em base direita e murmúrio vesicular abolido à esquerda. Exame laboratorial apresentava leucocitose com desvio para a esquerda (leucócitos: 17.340; bastão: 2\%; mielócitos: $2 \%)$ e PCR elevada (110 mg/L).

A figura 1A mostra a radiografia de tórax na admissão evidenciando derrame pleural em ambos os pulmões. No segundo dia de internação na UTI foi solicitado nova radiografia de tórax e observado aumento do derrame pleural à direita e piora à esquerda como evidenciado na figura $1 \mathrm{~B}$.
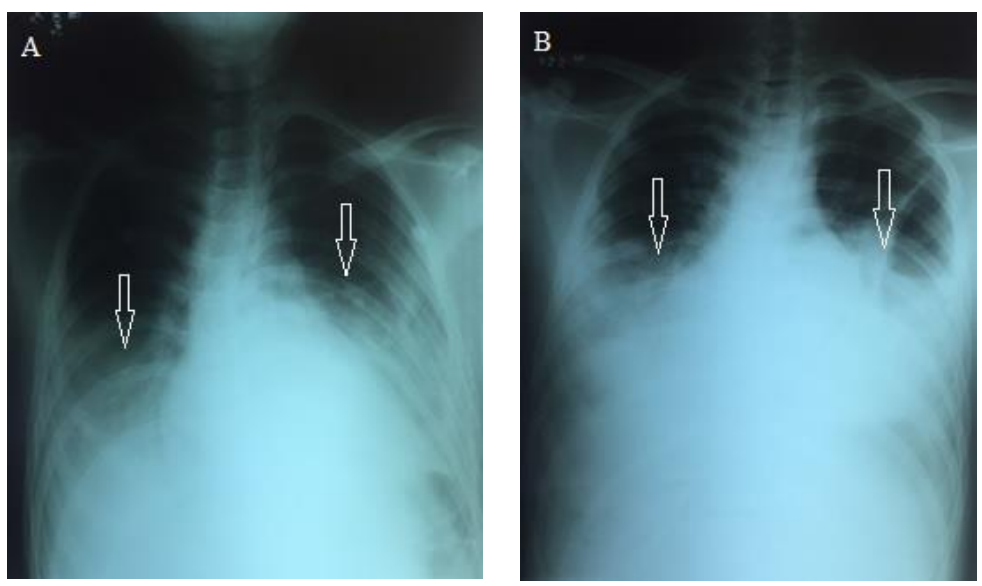
Figura 1: Radiografia de tórax: (A) na admissão; (B) segundo dia de internação em UTI. Setas indicam presença de derrame pleural.

Foi realizada toracocentese diagnóstica com drenagem de $135 \mathrm{ml}$ de líquido seroso (glicose: $90 \mathrm{mg} / \mathrm{dL}$; LDH: $3020 \mathrm{U} / \mathrm{L}$; Proteínas: $5000 \mathrm{mg} / \mathrm{dL}$ ) e iniciados Vancomicina e Piperacilina/Tazobactam.

No dia seguinte foram realizadas uma TC de tórax e USG abdominal total. A TC evidenciou Hidropneumotórax à esquerda, parcialmente septado; moderado derrame pleural à direita conforme visto na figura 2A. Na figura 2B observa-se a presença de nódulos ovalados com densidade de partes moles e tamanhos variados e esparsos, em ambos os pulmões. Há também consolidações parenquimatosas parcialmente cavitadas nas regiões subpleural anterior do segmento anterior do lobo superior direito e no seguimento lingular superior, além de colapso atelectásico dos segmentos basais de ambos os pulmões, mais proeminente à esquerda.
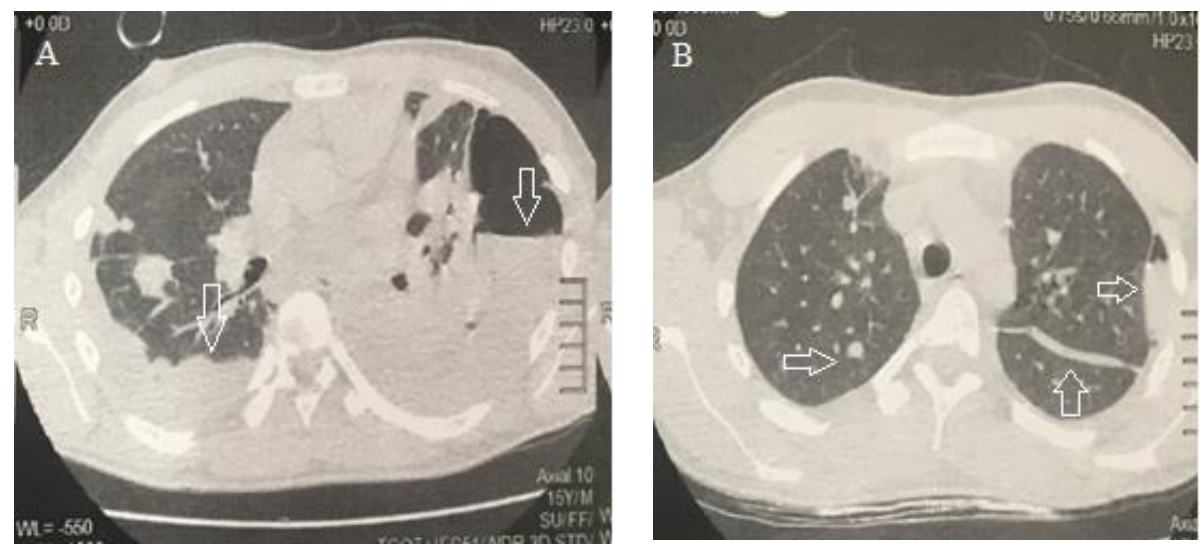

Figura 2: Tomografia computadorizada de tórax: (A) derrame pleural à direita e Hidropneumotórax à esquerda; (B) nódulos ovalados em ambos os pulmões e consolidações parenquimatosas parcialmente cavitadas nas regiões subpleural. Setas indicam as posições dos achados descritos acima.

USG mostrou discreto derrame pleural à direita e moderado à esquerda. Foi realizada a toracostomia com drenagem fechada à esquerda e sugerido controle radiológico para avaliar possível necessidade de decorticação pulmonar.

Em sua admissão na UTI, o paciente encontrava-se acordado, interagindo satisfatoriamente com o examinador, lúcido, orientado, cooperativo, acianótico, anictérico, mucosas hipocoradas (+/4+), hidratado e taquipneico, porém sem sinais de esforço respiratório em macronebulização com oxigênio a $8 \mathrm{~L} /$ minuto. Lesão em lábio inferior de aspecto edemaciado, sem evidência de tecido necrótico, com tecido de granulação e sem gânglios palpáveis em cabeça, pescoço ou tórax. Dreno de tórax à esquerda oscilante e com eliminação de conteúdo sanguinolento.

Exame físico:

ACV: RCR 2T, BNF S/S; FC: 90 bpm; PA: 150 x 93 mmHg.

AR: MV presente bilateralmente, diminuído em base esquerda e sem ruídos adventícios; FR: 37 irpm; SpO2: 96\%.

ABD: Peristalse audível nos quatro quadrantes, flácido, depressível, indolor à palpação superficial e profunda, sem sinais de irritação peritoneal.

MMII: Sem edemas, panturrilhas livres, pulso pedioso presente bilateralmente, cheios e simétricos.

Solicitado cultura do líquido pleural em cujo resultado não foi evidenciado o crescimento de bactérias patogênicas. Apresentava $45 \%$ de polimorfonucleares e 55\% de mononucleares e $0 \%$ de eosinófilos. Foi mantido esquema de antibioticoterapia com Vancomicina e Piperacilina/Tazobactam. 
No terceiro dia de internação apresentava dreno em hemitórax esquerdo sem oscilação respiratória e com drenagem, nas últimas $24 \mathrm{~h}$, de $200 \mathrm{~mL}$ de líquido hemático. Queixava-se de dificuldade para respirar. Foram intensificadas a analgesia, fisioterapia respiratória e ventilação mecânica não invasiva, com melhora do desconforto.

A figura 3A mostra o lábio inferior edemaciado e com tecido de granulação. A figura 3B mostra o lábio inferior dez dias após a admissão na UTI. O paciente apresentou boa resposta à antibioticoterapia e considerável melhora clínica, sendo transferido para a enfermaria de Clínica Médica, de onde evoluiu com alta hospitalar.
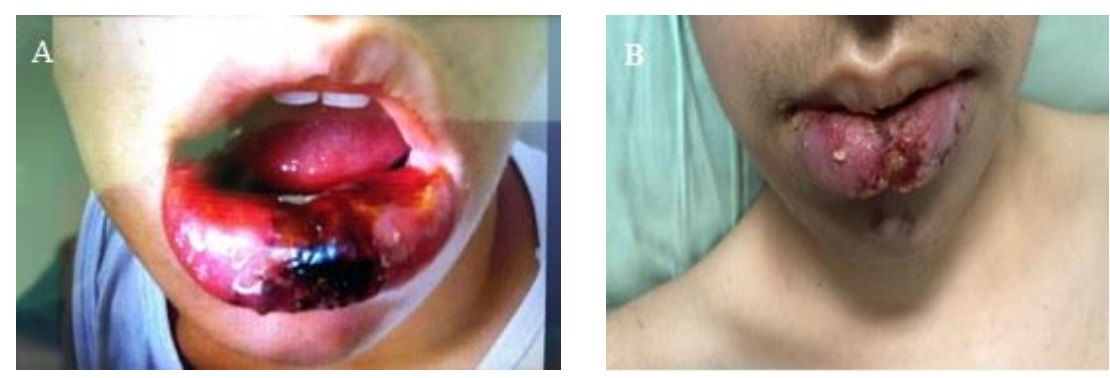

Figura 3: Lábio inferior: (A) edemaciado e com presença de tecido de granulação; (B) evolução após dez dias de internação em UTI.

\section{Discussão}

A pneumonia estafilocócica no adulto pode ser desencadeada após infecção viral por Influenza ou por disseminação hematogênica do estafilococo em decorrência de bacteremias, sepse, endocardite, entre outras condições, levando a um quadro radiológico diversos como condensações isoladas ou múltiplas, com tendência a cavitações ou formação de pneumatocele uni ou bilateral. (MANDELL, 2010, p. 2573-2578).

"É importante que os médicos estejam atentos aos casos de pneumonias comunitárias graves para a etiologia de estafilococo, principalmente durante a época da influenza e em pacientes com infiltrados pulmonares cavitários e necrosantes" (VERONESI, R.; FOCACCIA, R. 2015, p.1097).

Nos outros casos, como no relatado, a infecção pode ocorrer após disseminação hematogênica secundária à infecção de pele.

"Qualquer lesão localizada, por menor que seja, pode ser fonte potencial para a disseminação hematogênica da infecção" (VERONESI, R.; FOCACCIA, R. 2015, p.1098).

$\mathrm{O}$ paciente em questão apresentou um quadro agudo e lesão inflamatória em lábio, associado a nódulos pulmonares e derrame pleural, fazendo pensar em estafilococcia como a principal hipótese diagnóstica.

O aspecto radiológico pode assumir, inicialmente uma aparência de infiltrados redondos, únicos ou múltiplos, escavados ou não, distribuídos em ambos os hemitóraces, de padrão alveolar, pouco densos, com pequenas áreas de atelectasia, intercaladas de parênquima normal. Em alguns casos simulam metástases. As lesões, com o tempo, resultam em formações cavitárias de paredes finas, contornos regulares e conteúdo líquido conhecido como pneumatoceles. O comprometimento pleural é mais frequente nessa fase, ocasionando um derrame inicialmente serofibrinoso e que evolui, mais tarde, para empiema. [...] um aspecto importante à ser observado é a emergência de cepas de $\mathrm{S}$. aureus adquiridas na comunidade e resistentes à oxacilina que se apresentam na forma de infecções cutâneas e lesões disseminadas (CORREA DA SILVA et al., 2012, p 292).

Embora não tenha sido realizado o exame histopatológico, tal suspeita pôde ser confirmada após a excelente resposta clínica ao uso de antibioticoterapia com cobertura para estafilococo. 
Ainda que os achados tomográficos de cavitação pulmonar sejam comuns na tuberculose e a lesão labial possa sugerir doença fúngica associada, o quadro clínico apresentou evolução muito rápida para se pensar em doença granulomatosa do tipo fúngica ou tuberculosa.

Além disso, embora a criptococose evolua com nódulos, não é comum ocorrer derrame pleural em micose pulmonar. "Derrame pleural: descrito tanto no imunocompetente como no imunocromprometido, com frequência inferior a $10 \%$ dos casos de criptococose pulmonar" (GRUMACH, et al. 2008).

O exame radiológico do tórax pode mostrar desde consolidação segmentar ou lobar isolada, até múltiplos infiltrados no parênquima pulmonar. Infiltrados intersticiais ou de pequenos nódulos bilaterais são vistos na primeira fase da pneumonia. A suspeita radiológica de pneumonia estafilocócica deve ser aventada nos casos que evoluem com formação de cavitação, empiema e rápida evolução da consolidação pulmonar (VERONESI, R.; FOCACCIA, R., 2015, p. 1101).

Outro aspecto que deve ser bem avaliado pelo médico durante a abordagem terapêutica é a escolha do antibiótico em vista do aumento de cepas resistentes.

A resistência aos antibióticos é um problema crescente no tratamento das infecções por S. aureus. Os S. aureus resistentes à meticilina (MRSA) são resistentes à quase todos os antibióticos do grupo das penicilinas e cefalosporinas. Até recentemente, os MRSA eram principalmente encontrados em infecções hospitalares, contudo as infecções por MRSA adquiridas na comunidade estão se tornando comuns em muitas áreas. Como resultado, o tratamento empírico das infecções estafilocócicas com antibióticos do grupo das cefalosporinas e penicilinas se tornou menos eficaz (KUMAR at al., 2016, p. 375).

No paciente em questão houve boa resposta ao uso da Vancomicina em associação à Piperacilina/Tazobactam.

Estafilococo resistente a Meticilina é responsável por grande parte das infecções adquiridas no hospital e na comunidade, portanto a terapia empírica deve incluir antibióticos com cobertura para os mesmos.

A Vancomicina é o antibiótico de escolha para as infecções causadas por estafilococos resistentes à Meticilina, além de ser a primeira opção para a terapia intravenosa, tendo como alternativas a Daptomicina, Tigeciclina e Linezolida. Entretanto, já há relato de cepas de S. aureus com duas formas de resistência à vancomicina. Podem ser resistentes a níveis baixos de antibiótico quando a cepa possui parede celular espessa e desorganizada e são resistentes a níveis altos quando possuem o gene óperon Vana, sendo esta incomum (MURRAY at al., 2017, p. 182).

\section{Conclusão}

As pneumopatias causadas pelo estafilococo são menos frequentes na população quando comparadas a outros germes, como o pneumococo, porém uma vez instalada apresenta evolução rápida e elevada mortalidade. Portanto, deve-se sempre investigar a presença de estafilococo na vigência de lesão cutânea infecciosa associada a um quadro pulmonar e iniciar o tratamento empírico com cobertura para estafilococo o quanto antes, pois quanto mais rápido for iniciado o tratamento correto, maior a sobrevida dos pacientes.

\section{Referências}

GRUMACH, Anete Sevciovic et al. Consenso em criptococose-2008. Revista da Sociedade Brasileira de Medicina Tropical. Brasília. Vol. 41, n. 5 (set. /out. 2008), p. 524-544, 2008. 
KUMAR, V.; ABBAS, A. K.; ASTER, J. C. (Eds.). Robbins e Cotran: Patologia - Bases Patológicas das Doenças. 9a ed. Rio de Janeiro, RJ: Elsevier, 2016.

LONGO, DAN L.; KASPER, DENNIS L.; JAMESON, J.LARRY; FAUCI, ANTHONY S.; HAUSER, STEPHEN L; LOSCALZO, JOSEPH. Medicina Interna de Harrison. $18^{\mathrm{a}}$ ed. Porto Alegre, RS: AMGH Ed., 2013.

MANDELL, GERALD L; BENNETT, JOHN E; DOLIN, RAPHAEL. Mandell, Douglas and Bennett's Principles and Practices of Infectious Diseases. $7^{\mathrm{a}}$ ed. New York, Elsevier, 2010.

MURRAY, PATRICK R.; ROSENTHAL, KEN S.; PFALLER MICHAEL A. Microbiologia médica. 8. ed. Rio de Janeiro: Elsevier, 2017.

SILVA, LUIZ CARLOS CORREA DA.; HETZEL, JORGE LIMA.; FELICETTI, JOSÉ CARLOS.; MOREIRA, JOSÉ DA SILVA; CAMARGO, JOSÉ J.; PORTO, NELSON. Pneumologia - Princípio e Prática. Porto Alegre: Artmed, 2012.

VERONESI, R.; FOCACCIA, R. Tratado de Infectologia. 5a ed. São Paulo: Atheneu Ed., 2015. 